\title{
Características generales del recaudo y gasto público del Estado de Cundinamarca, 1856-1885
}

\section{General characteristics of tax collection and public expenditure of the state of Cundinamarca, 1856-1885}

\author{
Manuela Fonseca Gómez \\ Economista y Magíster en Economía de la Universidad de los Andes, Colombia \\ manuela.fonsecag@gmail.com \\ Edwin López Rivera \\ Candidato a doctor, Universidad de California, San Diego, Estados Unidos \\ https://orcid.org/0000-0001-5472-4010 \\ edwin.lopez@utadeo.edu.co
}

Fecha de recepción: 22 de noviembre de 2017 Fecha de aceptación: 22 de enero de 2018

Sugerencia de citación: Fonseca Gómez, M. y López Rivera, E. (2018). Características generales del recaudo y gasto público del Estado de Cundinamarca, 1856-1885. tiempo\&economía, 5(1), 41 -

56, doi: http://dx.doi.org/10.21789/24222704.1287

tiempo\&economía 


\section{RESUMEN}

El objetivo de este artículo es describir y analizar la evolución del recaudo fiscal y gasto público del Estado Soberano de Cundinamarca entre 1856 y 1885. En este periodo, el recaudo fiscal se vio afectado por los conflictos políticos y la falta de mecanismos legislativos para llegar a acuerdos democráticos sobre el sistema fiscal lo cual afectó sensiblemente el sistema tributario de Cundinamarca. Los enfrentamientos entre liberales y conservadores por ejercer el control sobre la administración local, las guerras y la amenaza de nuevos conflictos fueron fuentes adicionales de inestabilidad política que influyeron en las finanzas locales, puesto que dificultaron el cobro de impuestos en algunas localidades a la vez que se aumentaba el gasto militar.

Palabras clave: Cundinamarca, impuestos locales, gasto local, federalismo, historia económica

Códigos JEL: E62, N16, N46, N96

\section{ABSTRACT}

The objective of this paper is to describe and analyze the evolution of the tax collection and public expenditure of the Sovereign State of Cundinamarca between 1856 and 1885. In this period, political conflicts and the lack of legislative mechanisms to reach democratic agreements regarding the tax system affected the fiscal situation in Cundinamarca to a significant extent. Conflicts between liberals and conservatives for exercising control over local administration, and wars and the threat of new clashes were additional sources of political instability that affected local finances, affecting tax collection in some provinces and at the same time increasing military spending.

Keywords: Cundinamarca, local taxation, local expenditure, federalismo, economic history JEL Codes: E62, N16, N46, N96 
En este artículo se presenta la evolución del recaudo fiscal y el gasto público del estado soberano de Cundinamarca entre 1856 y 1885 y se estudian las causas políticas que generaron la variabilidad del recaudo y el aumento del gasto durante este periodo. El presente documento hace parte de una investigación más amplia en la que se estudian las reformas fiscales y el comportamiento de los ingresos y el gasto público de Cundinamarca entre 1850 y 1886.

Cundinamarca adquirió el estatus de Estado en 1857 cuando se publicó su primera Constitución en los inicios de la formación de la Confederación Granadina. Y perdió su autonomía en 1886 cuando pasó a ser un departamento, categoría administrativa creada bajo el régimen presidencial centralista de Rafael Núñez. En 1860, Cundinamarca contaba con un área de 6000 leguas cuadradas y una población de 350 mil habitantes aproximadamente, y estaba dividida administrativamente en cinco departamentos (Bogotá, Honda, Neiva, Purificación y Zipaquirá), los cuales contenían 14 centros urbanos: Bogotá, Neiva, Ibagué, Tocaima, La Palma, Honda, Ambalema, Guaduas, Guamo, Chocontá, Purificación, Ubaté, Zipaquirá y La Mesa (Martínez, 2002, p. 39). De estas ciudades, Bogotá, la capital de Cundinamarca y de la federación, fue la más poblada del país durante todo el periodo de estudio (Flórez y Romero, 2010), concentrándose en esta ciudad una parte significativa de la actividad económica del país y de Cundinamarca. La separación de las provincias de Mariquita y Neiva, que conformarían el Estado de Tolima en 1861, fue el cambio territorial y administrativo más importante a lo largo del periodo.

Las principales fuentes de información de este estudio son de tipo local y regional, producidas por distintas oficinas del Estado de Cundinamarca y de la provincia de Bogotá: leyes de presupuestos de ingresos y gastos, memorias de los secretarios de hacienda y del tesoro, memorias e informes de los Secretarios de Gobierno, memorias e informes del Secretario General e informes del Gobernador del Estado a la Asamblea Gubernamental. La forma en que esta información fue creada refleja la manera como se organizaron las instituciones y la burocracia de los estados soberanos, los cuales, en general, replicaron la estructura administrativa del estado federal. El poder ejecutivo en Cundinamarca lo ostentaba un gobernador elegido cada cuatro años, y el gasto público se asignaba a través de cuatro departamentos o partidas del gasto: Ejecutivo, Legislativo, Judicial y de Beneficencia y Recompensas. El primero era el más grande y en él se asignaban partidas para el mantenimiento de la burocracia del poder ejecutivo, la administración de hacienda, el crédito público, obras públicas, establecimientos educativos y la fuerza pública local. En el Departamento Legislativo se asignaban recursos para el funcionamiento de la Asamblea Legislativa del Estado, y en el Judicial se distribuían los fondos para el funcionamiento de los tribunales, el ministerio público, judicaturas locales y establecimientos carcelarios. El departamento más pequeño era el de Beneficencia y Recompensas en el cual se distribuían recursos para el funcionamiento de hospicios, hospitales, lazaretos y pagos a viudas o hijos de soldados que participaban en las guerras. Es importante considerar que los datos acá presentados se encuentran afectados por la evasión y elusión de impuestos. La ausencia de un catastro fuerte y de mecanismos de control sobre el recaudo a nivel local hacen que la información acá presentada no necesariamente refleje la producción total de impuestos en el Estado.

Si bien la historiografía fiscal del siglo xix y la historia económica en general han acudido intensivamente al uso de las Memorias de Hacienda producidas por el gobierno central, su equivalente local no ha sido explotado del mismo modo. A partir de estas fuentes se han logrado 
construir las series de ingresos y gastos para el gobierno central, con algunas referencias a los gobiernos locales, lo cual ha permitido mostrar el importante crecimiento de las rentas estatales entre 1851 y 1870 (Junguito, 2008), resultados que corroboran estudios previos donde se argumentaba que el federalismo tuvo un efecto positivo en el aumento de los ingresos tributarios tanto para los gobiernos locales como el federal (Deas, 1980; Ocampo, 1984). Sin embargo, a diferencia de la información generada a nivel central, las memorias de hacienda locales no fueron publicadas con la misma periodicidad, y en algunos casos su carácter fragmentario e incompleto refleja las dificultades de conformar una burocracia local competente en un estado todavía en ciernes. No obstante, estos documentos contienen importante información cuantitativa y cualitativa sobre el comportamiento de las contribuciones, impuestos, gastos y crédito de los gobiernos locales, no solo a nivel del estado, sino que en algunos casos de las provincias o subdivisiones territoriales que los conformaron.

Parte de la historiografía que ha abordado el estudio de los estados soberanos en el siglo XIX ha acudido a estas fuentes locales, haciendo un gran esfuerzo por recolectarlas e interpretarlas, ya que en algunos casos se encuentran dispersas en distintos archivos del país. Por ejemplo, el investigador Hernán Clavijo utiliza este tipo de información para estudiar las finanzas públicas del Estado de Tolima, el cual se separó de Cundinamarca con la Constitución de 1863. En particular, Clavijo estudia el papel de la renta de licores en el fisco y en la evolución política tolimense durante el periodo radical y en el periodo de la Regeneración hasta el estallido de la guerra de los Mil Días (Clavijo, 1993). Para el caso de Bolívar y las provincias del norte del país, se debe resaltar el importante esfuerzo de recopilar los informes de los presidentes y gobernadores del estado y las provincias, en los cuales se puede encontrar no solo valiosa información de tipo fiscal, sino del desarrollo político y social del norte del país a mediados del siglo XIX (Solano, 2007). En el caso del estado de Santander, y siguiendo el enfoque del trabajo de Clavijo, se ha estudiado la administración fiscal de la administración de la renta del aguardiente (Páez, 1998). Igualmente, existe un estudio general sobre distintos aspectos del estado soberano del Cauca entre 1858-1885 (Ortiz, 1986). El estudio del impacto de las reformas liberales en la organización administrativa de Cundinamarca también se ha basado en el análisis de estas fuentes locales (Gómez y Rueda, 2010). En años recientes, dichas fuentes locales de información han sido utilizadas de manera exhaustiva, lo cual ha permitido evaluar desde lo local los éxitos y fracasos de la economía y fiscalidad del federalismo colombiano (Kalmanovitz y López, 2010), así como de algunos casos concretos como el de Panamá (Kalmanovitz, 2012), Tolima (Pinto y Kalmanovitz, 2017), Santander (Pico, 2011, Zapata, 2015), Boyacá (Rosenthal, 2015), y Cundinamarca (Castillo y López, 2012).

El presente documento se compone de tres secciones, en la primera se presenta el comportamiento del ingreso; en la segunda, el del gasto; y en la tercera se presenta el balance fiscal.

\section{El comportamiento del ingreso}

La gráfica 1 muestra la evolución del recaudo por medio de leyes promulgadas en el Estado de Cundinamarca. El promedio de ingresos fiscales de Cundinamarca fue el segundo más alto durante el periodo 1856 - 1886, el cual no estaba muy lejos del nivel logrado por Antioquia que ocupaba el primer lugar. También, a pesar de que el ingreso cundinamarqués en 1848 
era muy similar al del resto de estados, su crecimiento en el mismo periodo fue de cerca del 10\% promedio anual, el más alto de todos los estados soberanos (Kalmanovitz y López, 2010, p. 219). Hacia 1873, la mayoría de sus ingresos fiscales provenían del cobro de peajes (36\%), la contribución directa (18\%), derechos de consumo (17\%) y degüello (14\%) (Kalmanovitz y López, 2010, p. 220). Los estados de Santander y Cundinamarca fueron los precursores del cobro del impuesto directo, el cual se estableció definitivamente en todo el país posteriormente, por medio de la ley 56 de 1918 (Díaz, 1997). Sin embargo, el cobro de peajes a su vez representó un obstáculo adicional para el desarrollo de un mercado interno. Esto, sumado a las dificultades del transporte, generaba que la distribución de mercancías al interior del Estado se diera a un costo más alto que en el resto del país.

Gráfica 1. Ingreso en el Estado de Cundinamarca 1857 - 1885

(Pesos corrientes)

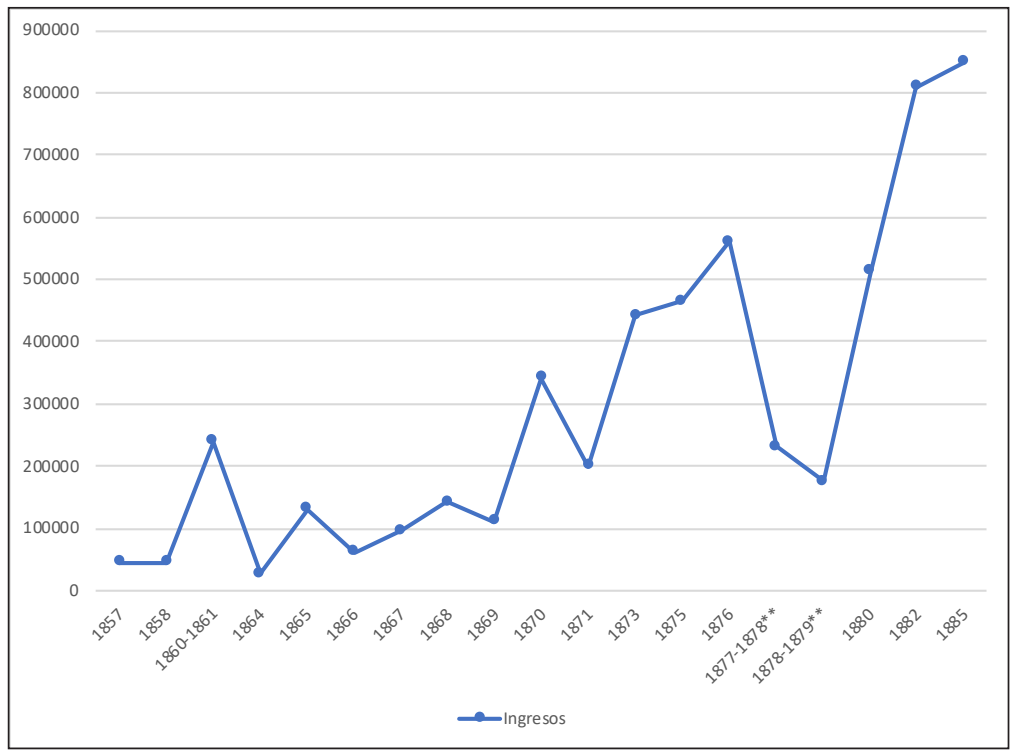

Fuente: leyes de presupuesto de rentas y gastos del Estado Soberano de Cundinamarca, 1856-1883.

La modernización del sistema tributario en Cundinamarca generó un aumento significativo del recaudo fiscal por habitante en comparación con el periodo anterior a 1848. Dicho aumento contribuyó a que el estado de Cundinamarca se convirtiera durante el federalismo en uno de los estados más ricos de la unión (Deas, 1980, p. 155) el cual tenía ingresos cinco veces y medio más altos que Magdalena, el más pobre. La búsqueda de la modernización y el progreso social que permeaba las reformas liberales, frecuentemente se manifestaba en un constante cambio en las reglas de juego, entre ellas las que tenían que ver con la organización fiscal del Estado. Muestra de esto son las siete Constituciones del Estado que se redactaron entre 1857 y 1880 , los sucesivos códigos comercial, fiscal, educación, beneficencia y fomento y los múltiples decretos y leyes que reformaban tasas y bases impositivas de los impuestos cobrados. Otra forma de obtener ingresos era a través de préstamos que solicitaba el gobierno Cundinamarqués tanto al gobierno central como a inversionistas privados, como la banca privada que surgió 
en la década de 1860. La inestabilidad política se manifestó más en la volatilidad del recaudo fiscal que en el monto recaudado, el cual fue relativamente alto y creciente durante el periodo federal. Las guerras y los conflictos entre las élites en Cundinamarca explican la fuerte variabilidad de la serie de ingresos fiscales tanto en términos nominales como reales.

A pesar del crecimiento sostenido de los ingresos, la volatilidad también fue alta, la cual está explicada por los desórdenes políticos y conflictos bipartidistas del Estado, pero también de la Unión. En 1862 se frenó de manera drástica el crecimiento del recaudo fiscal iniciado a finales de la década de 1850. Las finanzas públicas cundinamarquesas fueron muy sensibles a las revueltas populares en contra de las reformas liberales del presidente Tomás Cipriano de Mosquera, en especial la expropiación de bienes de manos muertas en propiedad de la Iglesia. Las alteraciones del orden público derivaron en levantamientos armados por parte de guerrillas conservadoras en Cundinamarca, especialmente en los municipios de Lenguazaque, Sumapaz y la región oriental. En 1865 surge un nuevo alzamiento armado por parte de los conservadores en contra del presidente del Estado, Daniel Aldana, y para 1868 se dio un intento de intervención del gobierno central y la asamblea local para derrocar al gobernador del Estado, el conservador Ignacio Gutiérrez.

Para 1870, los ingresos habían alcanzado un nivel considerable respecto al quinquenio anterior, sin embargo, en 1871 el ingreso volvió a caer. Esta caída en los ingresos se explica por la guerra y las expectativas de guerra que se reflejan en el aumento en el gasto en fuerza pública (aumentó de \$10.000 en el año anterior a \$36.000) debido al Golpe de Estado en 1870 por las disputas ideológicas entre conservadores y liberales. El Estado enfrenta su mayor crisis fiscal en la segunda mitad de la década de 1870. El descontento de los liberales radicales por la posesión del Gobernador elegido en 1874 y el alzamiento de las guerrillas ${ }^{1}$ conservadoras en 1876 en contra del presidente de la unión, Aquileo Parra, explican la fuerte caída del ingreso para las vigencias de 1877-1878 y 1878-1879.

La evolución de la estructura del recaudo también muestra que la implementación de un impuesto directo que reemplazara los vestigios tributarios de la vieja estructura colonial fue en gran parte un proceso de ensayo y error. Antes de la creación del impuesto directo, en 1858, los ingresos más importantes del Estado eran bienes raíces que representaba un $21 \%$ del recaudo total, papel sellado cuyo recaudo ascendía a 18\% del total, bienes del Estado 17\%, hipotecas y registro $15 \%$ y por último el de caminos cuyo recaudo fue el $13 \%$ del total. Por estos años los ingresos en bienes del Estado aumentaron bastante gracias a la política de enajenación de bienes de manos muertas en propiedad de la Iglesia. Para 1865 el 46\% del recaudo correspondió a la contribución directa, el $27 \%$ al impuesto de caminos y el $15 \%$ al impuesto de degüello, los cuales se constituirían en los principales impuestos que recaudaría el Estado hasta el final del periodo. La tributación directa mantendría proporciones similares durante la década de 1860, mientras que el impuesto de degüello llegó a representar el $23 \%$ del recaudo en 1869, a lo cual se sumaban impuestos que aparecían de manera intermitente como el de timbre que alcanzaría el $11 \%$ del total recaudado y el de hipotecas con el $8 \%$. En la década de 1870 el experimento de tributación directa en Cundinamarca empieza a agotarse, siendo reemplazado por el impuesto de degüello, así como por el cobro de impuestos a bienes raíces, mercancías extranjeras y consumo. Para 1878 de los 217.000 pesos recaudados, 40\% fueron

1 Estas guerrillas se concentraron principalmente en Guasca, Soacha y Sopó. 
por concepto de impuesto al degüello, 22\% de cobro a la circulación de mercancías extranjeras, $13 \%$ de bienes raíces, $9 \%$ por impuesto de timbre y $7 \%$ por derechos de consumo e hipotecas y registro.

La planeación presupuestal muestra el gran interés que tuvieron las distintas administraciones por mantener y fortalecer el impuesto directo a través de los años, en particular por el importante rol que desempeñaba este tipo de impuestos en la ideología liberal. Sin embargo, fue un impuesto que generó gran oposición entre los más ricos del Estado, ya fueran liberales o conservadores, quienes ocultaban su riqueza grabable al Estado. A esto se suma la incapacidad del ejecutivo local para mantener un registro efectivo de los ingresos y las propiedades de sus habitantes mediante la conformación de un registro catastral efectivo que diera cuenta de la riqueza de sus habitantes. Tampoco el Estado estuvo en la capacidad burocrática de elaborar listados de contribuyentes ni de ejercer vigilancia y control sobre los recursos recaudados por la Administración General de Hacienda, lo cual generaba desconfianza entre los contribuyentes (Gómez y Rueda, 2010, p. 214). De igual manera, la descentralización al interior del Estado también se prestó para que los administradores de las administraciones regionales de impuestos no declararan a la general todo el ingreso recaudado, aprovechándose de la falta de comunicación y control que se ejercía sobre sus administraciones (Velandia, 2004).

Los enfrentamientos entre los partidos por ejercer el control sobre la administración local fueron una fuente de inestabilidad política que afectaba las finanzas locales. Estos conflictos eran aprovechados por líderes políticos locales, quienes persuadían a la población para que protestaran en contra de los supuestos abusos de funcionarios de la Administración de Hacienda, generando de esta forma tensiones entre la población y la administración (Gómez y Rueda, 2010). Finalmente, a las vicisitudes políticas propias del Estado se sumaban los conflictos nacionales, los cuales se llevaban a cabo de manera importante en Bogotá en su doble calidad de capital del Estado y de la unión, y donde residía la élite política y en la cual se tomaban las decisiones políticas, administrativas y culturales que afectaban a todo el país. Por tal razón, las guerras nacionales que se libraron durante la época federal también afectaron la estabilidad política y económica del estado cundinamarqués (Gómez y Rueda, 2010).

\section{El comportamiento del gasto}

La información disponible sobre gasto público presupuestado ${ }^{2}$ en Cundinamarca muestra que la mayoría del ingreso fiscal del Estado se utilizó para cubrir los gastos generados por las guerras, mejorar la red de caminos locales y el funcionamiento la administración del Estado. Aunque se aprecia un aumento en el gasto en instrucción pública, su participación en el gasto total fue bajo.

2 Si bien no es el gasto que efectivamente realizó la administración estatal, esta serie muestra las expectativas de gasto que tenían las autoridades fiscales, las cuales por lo general se "corregían" a lo largo del año fiscal mediante la expansión del crédito o adiciones presupuestales para expandir las crecientes necesidades de gasto. 
Gráfica 2. Gasto Presupuestado en el Estado de Cundinamarca 1857 - 1885

(Pesos corrientes)

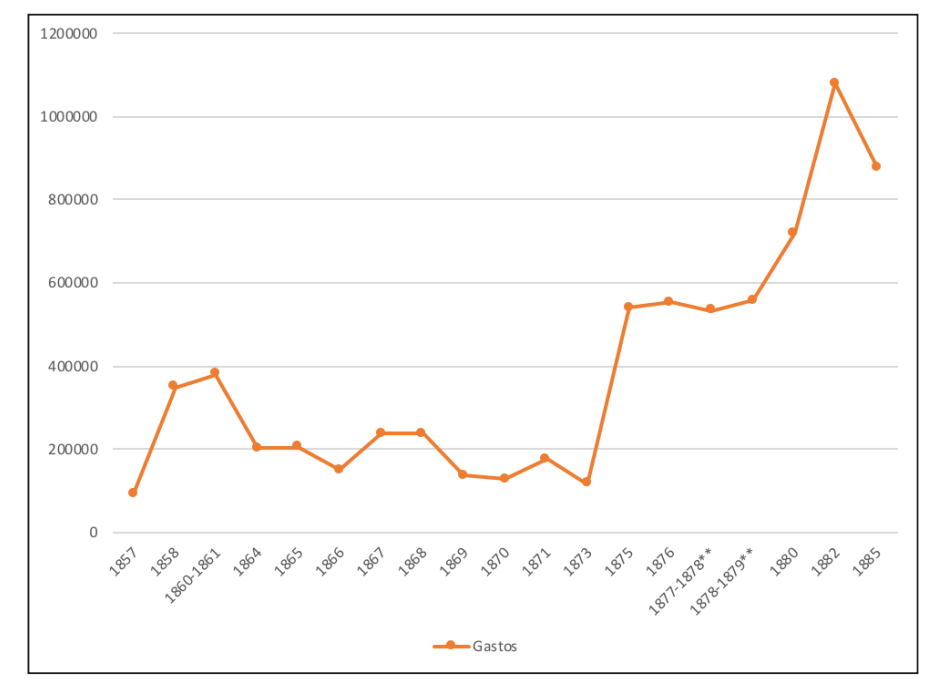

Fuente: leyes de presupuesto de rentas y gastos del Estado Soberano de Cundinamarca, 1856-1883.

En la Gráfica 2 se pueden identificar dos periodos: de 1856 a 1873, y de 1874 a 1885 . El primero refleja las vicisitudes de los primeros años de la creación del estado soberano de Cundinamarca (creado en 1857), seguido por la guerra de las soberanías, de 1859 a 1861, la cuarta gran guerra civil que tuvo el país en el siglo XIX (Tirado, 1989), y que significó un importante esfuerzo fiscal y administrativo para el estado de Cundinamarca. La guerra surgió en el Estado soberano del Cauca y se extendió por todo el país, bajo el liderazgo de Tomás Cipriano de Mosquera con la intención de limitar el poder del gobierno central sobre las regiones, el cual se ejercía por el conservador Mariano Ospina desde Bogotá, capital de la confederación y del estado de Cundinamarca. En 1859, el gobierno nacional promulgó leyes sobre la Hacienda, el territorio y las elecciones que incitaron a esta guerra por considerar que atentaban contra la soberanía de las regiones (Uribe y López, 2008). La Confederación ya había enviado sus tropas a varias regiones y se vio en la necesidad de exigir al gobierno del Estado de Cundinamarca la organización de la Guardia Municipal que sería llamada a prestar servicio una vez se declarara la guerra.

Una consecuencia de la guerra de las soberanías fue que el poblado de Funza reemplazó por un tiempo a Bogotá como capital de Cundinamarca, dejando a esta última como Distrito Federal o capital de la Unión. En 1863, el secretario de Gobierno de Cundinamarca, José María Baraya, encargado también del despacho de Hacienda, informó a la Asamblea Constituyente del Estado que Bogotá debería volver a ser parte del Estado de Cundinamarca, así como lo fue desde su creación como estado soberano en 1857 por el bien de los bogotanos y de los cundinamarqueses. Para Baraya:

Bogotá es la ciudad más importante de la Unión Colombiana, la más populosa, la más rica, la más civilizada. Pero si Cundinamarca gana bajo todos los aspectos con esa incorporación, para Bogotá no es menos conveniente, porque sus habitantes tienen en Cundinamarca la mayor parte de sus intereses, de sus relaciones, de su fortuna y de su porvenir. Por lo mis- 
mo, Bogotá ha estado y está de hecho en Cundinamarca, y lo que se va a hacer es a reconocer y declarar este hecho con la incorporación legal prevenida, dándole la parte que debe tener en el Gobierno del Estado. (Informe Secretario Gobierno, 1863, p. 7)

En términos generales, el informe de Baraya reconoce la dinámica y privilegiada situación económica de la capital y la conveniencia de poder extraer impuestos de los negocios y los habitantes de la capital.

Con respecto a la situación de orden público después de la guerra de las soberanías, el secretario de Gobierno comenta que luego del sometimiento de las guerrillas de Guasca y Sopó en noviembre de 1862, el poder ejecutivo había mantenido la paz y el orden en el Estado "a pesar de los elementos anárquicos que deja en pos una guerra larga, tenaz i sangrienta como la que acaba de sufrir el país" (Informe Secretario Gobierno, 1863, p. 3). El interés de la administración cundinamarquesa por mantener el orden público y promover el progreso económico se ve reflejado en la significativa partida destinada en el presupuesto de gasto de 1864 al mantenimiento del pie de fuerza y su dotación de armas, y junto con este, el rubro de gasto para la reparación de caminos estropeados durante la guerra. Así, el Estado destinó el 69\% de los gastos del Departamento Ejecutivo al sostenimiento del pie de fuerza y a las vías de comunicación (tablas 1 y 2).

Tabla 1. Presupuesto de gastos para el Estado soberano de Cundinamarca

\begin{tabular}{|c|c|c|}
\hline Créditos abiertos al poder ejecutivo & Valor (pesos \$) & Porcentaje del total \\
\hline Departamento Legislativo & $5.765,4$ & $3 \%$ \\
Departamento Ejecutivo & $166.514,0$ & $82 \%$ \\
\cline { 2 - 3 } Departamento Judicial & $26.736,0$ & $13 \%$ \\
\cline { 2 - 3 } Beneficencia y recompensas & $3.125,0$ & $2 \%$ \\
\cline { 2 - 3 } & $202.140,4$ & $100 \%$ \\
\hline Total & &
\end{tabular}

Fuente: Ley 24 de diciembre de 1863, de Presupuesto de gastos del Estado para el año 1864. Cálculos propios.

En el marco de la Constitución de Rionegro de 1863, los liberales radicales llevaron a cabo reformas económicas de gran importancia como la descentralización fiscal y la desamortización de bienes de manos muertas (Meisel, 2011). Consecuentemente, los liberales buscaron la separación del Estado y la Iglesia, y como parte de esta estrategia la reforma educativa de 1870 erradicaba la influencia de la iglesia sobre la educación, y procuraba aumentar su cobertura y mejorar su calidad. El Decreto Orgánico de $1^{\circ}$ de noviembre de 1870 promulgado por el presidente Eustorgio Salgar estableció un sistema de escuelas públicas, laicas y gratuitas. Para lograr este cometido, el gobierno comisionó una misión de nueve maestros egresados de 
universidades alemanas, uno para cada Estado de la Unión, con el objetivo de implantar una escuela normal donde serían formados con métodos pedagógicos modernos los maestros de los niños colombianos, aprovechando así los avances del prestigioso sistema educativo alemán de mediados del siglo xıx (Meisel, 2011, pp. 6-8).

Tabla 2. Presupuesto de gastos para 1864 de los capítulos de fuerza pública y vías de comunicación. Estado Soberano de Cundinamarca

\begin{tabular}{|c|c|c|c|}
\hline \multicolumn{2}{|c|}{ Componentes del presupuesto de gastos Departamento Ejecutivo } & Valor (pesos \$) & $\begin{array}{c}\text { Porcentaje } \\
\text { de gastos del } \\
\text { Departamento }\end{array}$ \\
\hline \multirow{2}{*}{$\begin{array}{l}\text { Capítulo VI. } \\
\text { Fuerza Pública }\end{array}$} & $\begin{array}{l}\text { Art único. Para el mantenimiento de los } 500 \\
\text { hombres mandados sostener en tiempo de } \\
\text { paz por la ley de } 5 \text { de setiembre de } 1862 \\
\text { (aproximación) }\end{array}$ & 86.000 & $52 \%$ \\
\hline & $\begin{array}{c}\text { Art } 2^{\circ} \text {. Para comprar } 1,000 \text { fusiles, conforme a la } \\
\text { misma ley (aproximación) }\end{array}$ & 8.000 & $5 \%$ \\
\hline $\begin{array}{l}\text { Capítulo XI } \\
\text { Vías de } \\
\text { Comunicación }\end{array}$ & $\begin{array}{l}\text { Art único. Para la reparación, conservación y } \\
\text { construcción de caminos (aproximación) }\end{array}$ & 21.000 & $13 \%$ \\
\hline \multicolumn{2}{|r|}{ Total capítulos VI y XI } & 115.000 & $69 \%$ \\
\hline \multicolumn{2}{|r|}{ Total del Departamento Ejecutivo } & 166.514 & $100 \%$ \\
\hline
\end{tabular}

Fuente: Ley 24 de diciembre de 1863, de Presupuesto de gastos del Estado para el año 1864. Cálculos propios.

Una vez puesto en marcha el programa de educación laica en 1871, el Secretario General de Cundinamarca informó que en 1873 todos los pueblos del Estado y en muchos caseríos se habían establecido escuelas, y el número de alumnos que asistían a ellas era considerablemente alto y creciente (Informe Secretario General, 1873, p. 16). El secretario también consideraba que "los métodos de enseñanza alemanes están produciendo resultados maravillosos. No hay quien no lo reconozca así. Sin duda alguna se han abierto de par en par las puertas de la civilización y del bienestar a nuestro pobre pueblo" (Informe Secretario General, 1873, p. 16).

Tanto la administración del Estado como de la unión compartían los gastos para el sostenimiento de las escuelas normales de institutores y de mujeres. Por ejemplo, en el caso de la escuela normal de Institutores de varones, para el periodo fiscal $1872-1873$, los gastos se repartieron de la siguiente forma: 
Tabla 3. Repartición de gastos de sostenimiento de la escuela normal de Institutores de varones, 1872 - 1873

\begin{tabular}{|c|c|}
\hline \multicolumn{2}{|c|}{$\begin{array}{l}\text { Gastos hechos por el Tesoro de la Unión en la Escuela Normal de Institutores, } \\
\text { del } 1 \text { de setiembre de } 1872 \text { a } 30 \text { de noviembre de } 1873 \text {, son (pesos \$): }\end{array}$} \\
\hline Sueldos del director y subdirector de la Escuela Normal & $2.410,75$ \\
\hline Empleados auxiliares de la misma Escuela & 180,00 \\
\hline Alimentación de superiores y alumnos-maestros de la Escuela & $2.092,90$ \\
\hline Arrendamiento del local de la misma Escuela & 720,00 \\
\hline Útiles para la Escuela Normal & 331,30 \\
\hline Suma & $5.734,95$ \\
\hline \multicolumn{2}{|c|}{$\begin{array}{l}\text { Los gastos que ha erogado el Estado de Cundinamarca en el sostenimiento de la misma } \\
\text { Escuela Normal en el año transcurrido de } 1^{\circ} \text { de diciembre de } 1872 \text { a } 30 \text { de noviembre de } 873 \text {, } \\
\text { son (pesos \$): }\end{array}$} \\
\hline Sueldo del profesor de música y canto & 200,00 \\
\hline Alimentación de los alumnos-maestros que sostiene el Estado & $2.069,50$ \\
\hline Textos suministrados a los mismos alumnos & 128,85 \\
\hline Gastos varios & 19,50 \\
\hline Suma & $2.417,85$ \\
\hline
\end{tabular}

Fuente: Tercer Informe Anual del director de la Instrucción Pública del Estado Soberano de Cundinamarca, 1873, pp. 16-17.

En cuanto al nivel departamental al interior del Estado, la relación de egresos del 1 de enero al 31 de octubre de 1873 muestra que el Departamento del Centro, en el cual se encontraba la ciudad de Bogotá, concentró los mayores egresos. Igualmente, la mayor parte del gasto de este departamento se asignó para el funcionamiento del Departamento Ejecutivo, seguido por el Judicial. Esto contrasta con el resto de las subdivisiones territoriales del Estado, donde el Departamento Judicial absorbe la mayor parte de los recursos.

A partir de 1874 y hasta 1885 la serie de gasto presupuestado muestra una tendencia creciente, lo cual coincide con la guerra de 1876-1877, la quinta guerra civil del siglo xIx en Colombia. Varios factores se conjugaron para desencadenar esta guerra. En primer lugar, la crisis económica mundial iniciada en 1873 propició la caída de las exportaciones de tabaco y oro en la década de 1870. También, después de 14 años en el poder, el desgaste de los gobiernos del radicalismo liberal era evidente, a lo cual se sumó el rechazo de los conservadores al proyecto de educación liberal que buscaba implementar una educación laica, obligatoria y gratuita. El estado de Cundinamarca fue un escenario importante de la guerra, especialmente con la participación de las guerrillas de Mochuelos y Guascas (Ortiz, 2004). 
Tabla 4. Relación de movimiento de gastos del 1 de enero al 31 de octubre de 1873

\begin{tabular}{|c|c|c|}
\hline Egresos & Valor (\$) & Porcentaje del respectivo costo \\
\hline Departamento del Centro & 87949,45 & $100 \%$ \\
\hline Departamento Legislativo & 4301,60 & $5 \%$ \\
\hline Id. Ejecutivo & 44129,05 & $50 \%$ \\
\hline Id. Judicial & 29943,25 & $34 \%$ \\
\hline Id. De la Deuda Pública & 3720,60 & $4 \%$ \\
\hline $\begin{array}{c}\text { Beneficencia, gastos del Tesoro, créditos } \\
\text { pasivos de } 1872\end{array}$ & 5854,95 & $7 \%$ \\
\hline Departamento de Tequendama & 7526,72 & $100 \%$ \\
\hline Departamento Ejecutivo & 2521,82 & $34 \%$ \\
\hline Id. Judicial & 5004,90 & $66 \%$ \\
\hline Departamento de Occidente & 7235,15 & $100 \%$ \\
\hline Departamento Ejecutivo & 2749,05 & $38 \%$ \\
\hline Id. Judicial & 4208,70 & $58 \%$ \\
\hline Créditos pasivos de 1872 & 277,40 & $4 \%$ \\
\hline Departamento del Norte & 5355,67 & $100 \%$ \\
\hline Departamento Ejecutivo & 1928,95 & $36 \%$ \\
\hline Id. Judicial & 3426,72 & $64 \%$ \\
\hline Departamento de Ubaté & 7371,67 & $100 \%$ \\
\hline Departamento Ejecutivo & 3138,57 & $43 \%$ \\
\hline Id. Judicial & 4233,10 & $57 \%$ \\
\hline Total de egresos del Estado & 115438,67 & \\
\hline
\end{tabular}

Fuente: cálculos propios con base en Informe Secretario de General al Gobernador de Cundinamarca 1873. Documentos: Informe del Administrador General de Hacienda, pp. 35-38.

Esta guerra afectó significativamente las finanzas del Estado, lo que se reflejó en la dificultad para recaudar los impuestos y en el aumento del gasto. El Secretario de Hacienda en su memoria de 1879 comentaba que el aumento de fuerza pública que se decretó en los primeros meses de 1879 como consecuencia de la guerra, representó un aumento considerable del gasto (Memoria Secretario de Hacienda, 1879, pp. 10-11).

\section{Balance fiscal y contexto político}

El creciente gasto militar y en infraestructura, los desórdenes políticos, la difícil consolidación de una estructura tributaria en torno a la tributación directa, y la volatilidad del recaudo produjeron un balance fiscal deficitario, como se muestra en la gráfica 3. Tan solo durante la primera mitad de la década de 1870 el Estado logró generar un superávit debido al bajo nivel de gasto el cual se mantuvo relativamente constante entre 1869 y 1873, así como al creciente recaudo fiscal del periodo 1869-1875, salvo la caída de 1871 que impactó también el balance. La crisis política y fiscal de la parte final del periodo federal hacen que Cundinamarca vuelva a incrementar su déficit el cual se reduce hasta su desaparición como estado soberano. 
Tabla 5. Gastos de enero a junio 1879 de los departamentos del Estado de Cundinamarca (pesos)

\begin{tabular}{|c|r|r|}
\hline Departamentos & \multicolumn{1}{|c|}{ Ingresos } & \multicolumn{1}{c|}{ Gastos } \\
\hline Departamento de Bogotá y Oriente & $94.897,32$ & $111.725,70$ \\
De Zipaquirá & $8.680,77$ & $7.765,50$ \\
De Facatativá & $9.351,00$ & $9.351,00$ \\
De Tequendama & $8.723,20$ & $7.689,95$ \\
De Ubaté & $7.942,90$ & $7.207,10$ \\
\hline Totales & $129.595,20$ & $143.739,25$ \\
\hline
\end{tabular}

Fuente: Memoria del Secretario de Hacienda del Estado soberano de Cundinamarca, 1879, p. VII.

Gráfica 3. Déficit Fiscal $1857-1885$

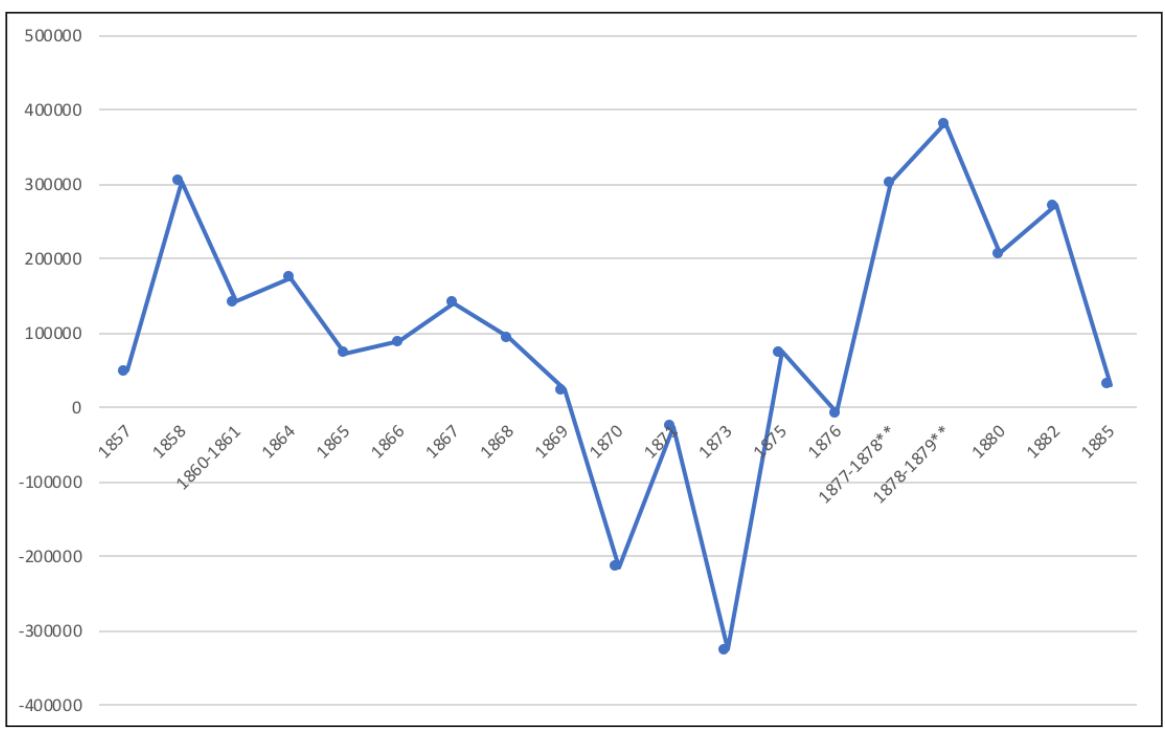

Fuente: cálculos propios con base en Leyes de presupuesto de rentas y gastos del Estado Soberano de Cundinamarca, 1856 - 1883.

Como lo muestran los distintos informes del Secretario de Hacienda, la deficiencia en los ingresos respecto a los elevados gastos, ocasionaron la necesidad de contratar créditos adicionales ya fuera con prestamistas locales o acudiendo a la subvención nacional o recursos aportados a manera de préstamo por el gobierno central. Por ejemplo, los recursos provenientes del crédito contratado en 1879 se adjudicaron al departamento judicial con el fin de cubrir los gastos de la casa de penitencia. En 1874, el gobierno destinó una suma considerable para la reparación de víctimas de la guerra de ese año a través de erogaciones generadas por los departamentos del tesoro y de beneficencia, las cuales fueron financiadas con deuda. Hacia 
finales del periodo federal, en 1884, el crédito adicional solicitado se destinó para cubrir los gastos del departamento de vías de comunicación y en segundo lugar para el ejecutivo. Nuevamente, los desórdenes políticos explican el volátil nivel de ingreso y los continuos déficits fiscales en el Estado.

\section{Conclusiones}

A pesar del crecimiento de largo plazo que se aprecia en la serie de ingresos fiscales en Cundinamarca a partir de 1863, la principal característica del recaudo es la volatilidad. Sin embargo, en el contexto de la unión, la evolución del recaudo le sirvió a Cundinamarca para fortalecer sus finanzas, logro compartido con el Estado soberano de Antioquia. La estructura fiscal del Estado y las sucesivas reformas a la estructura de impuestos afectaron este crecimiento de las rentas, en las cuales el degüello, los impuestos al comercio, las aduanas internas y, sobre todo, el impuesto directo, tuvieron un papel protagónico. Las aduanas internas y los derechos de caminos pudieron ofrecer cierta protección a la economía local que favorecieron el crecimiento regional.

Esto deja entrever que las fuentes de ingreso fiscal del Estado no estaban diversificadas y dependían casi exclusivamente de unos pocos rubros, especialmente en la década del 1860. Ya para los años 1870, entraron de manera intermitente otros impuestos y contribuciones como hipotecas, multas y el papel sellado, las cuales nunca se consolidaron generando cierta inestabilidad en la estructura fiscal. Si bien el federalismo en Cundinamarca sirvió para abolir definitivamente los impuestos coloniales, nunca hubo un acuerdo consensuado sobre los impuestos que los reemplazarían, y aunque la contribución directa fue importante en los primeros años del Estado, la renta de caminos y de consumo serían los impuestos más exitosos y permanentes.

Finalmente, los conflictos políticos y la falta de mecanismos legislativos para llegar a acuerdos democráticos sobre el sistema fiscal afectaron sensiblemente el sistema tributario de Cundinamarca. Los enfrentamientos entre los partidos por ejercer el control sobre la administración local también fueron una fuente de inestabilidad política que afectaba las finanzas locales. Igualmente, las guerras y la amenaza de nuevos conflictos causaron frecuentes estragos en el erario del Estado, lo que se manifestó en la dificultad para recaudar impuestos y en el aumento del gasto para atender los requerimientos de la creciente la fuerza pública.

\section{Referencias}

\section{Fuentes primarias}

Informe del gobernador de la Provincia de Bogotá 1856. Presupuesto provincial de gastos para el servicio del año económico de 1856 a 1857.

Informe del Secretario de Gobierno de Cundinamarca, 1863. 
Tercer Informe Anual del director de la Instrucción Pública del Estado Soberano de Cundinamarca, 1873.

Informe del Secretario de General al Gobernador de Cundinamarca, 1873.

Decreto 130 de 1878 sobre liquidación de gastos del presupuesto de 1879.

Memoria del Secretario de Hacienda del Estado soberano de Cundinamarca, 1879.

Leyes de presupuesto de rentas y gastos de los años: 1857, 1859, 1863, 1864, 1866, 1867, 1868,1869, 1870, 1874, 1875, 1876, 1877, 1878, 1880, 1881, 1882, 1883, 1884.

\section{Fuentes secundarias}

Castillo, A. y López, E. (2012). Federalismo y reformas institucionales en Cundinamarca 18481890. Documentos de Trabajo en Economía. Bogotá: Universidad de Bogotá Jorge Tadeo Lozano.

Clavijo, H. (1993). Monopolio fiscal y guerras civiles en el Tolima, 1865-1899. Boletín Cultural y Bibliográfico, 32. Bogotá: Banco de la República.

Deas, M. (1980). Los problemas fiscales en Colombia, durante el siglo XIX. J. A. Ocampo, comp., Ensayos sobre historia económica colombiana, Bogotá: Fedesarrollo.

Díaz, S. B. (1997). Finanzas públicas del gobierno central en Colombia 1905-1925. Historia Crítica, 14, 59-79.

Flórez, C. E. y O. L. Romero. (2010). La demografía de Colombia en el siglo XIX. En M. Adolfo y M. T. Ramírez, La Economía Colombiana del siglo XIX. Bogotá: Banco de la República.

Gómez Contreras, E. y J. E. Rueda E. (2010). La república liberal decimonónica en Cundinamarca, 1849-1886. Aspectos políticos y administrativos. Bogotá: Escuela Superior de Administración Pública.

Junguito, R. (2008). Las finanzas públicas en el Siglo XIX. Borrador. Bogotá: Banco de la República.

Kalmanovitz, S. (2012). El federalismo y la fiscalidad del Estado Soberano de Panamá, 18501886. Revista de Economía Institucional, 14(27), 99-145.

Kalmanovitz, S. y López, E. (2010). Las finanzas públicas de la Confederación Granadina y los Estados Unidos de Colombia 1850-1886. Revista de Economía Institucional, 12(23), 199-228.

Martínez, A. (2002). La Experiencia Federal en Colombia. Bucaramanga: Universidad Industrial de Santander y Colciencias. Sin Publicar.

Meisel Roca, A. (2011). El sueño de los radicales y las desigualdades regionales en Colombia: La educación de calidad para todos como política de desarrollo territorio. Documentos de Trabajo de Economía Regional. Cartagena: Banco de la República.

Melo, J. O. (2004). Las vicisitudes del modelo liberal. En: J. A. Ocampo, Historia Económica de Colombia. Bogotá: Planeta. 
Mendoza Chacón, Y. C. (2011). Un acercamiento a la fuerza pública en los estados de Cundinamarca y Santander, 1857-1885. Anuario de Historia Regional y de las Fronteras, 16(1), 125-150.

Ocampo, J. A. (1984). Centralismo, descentralización y federalismo en la historia colombiana. En: Ocampo, J.A., y S. Montenegro, eds. Crisis Mundial, Protección e Industrialización: Ensayos de Historia Económica Colombiana (pp. 345-366). Bogotá.

Ortiz Mesa, L. J. (2004). Fusiles y Plegarias. Guerra de guerrillas en Cundinamarca, Boyacá y Santander, 1876-1877. Bogotá: Universidad Nacional de Colombia.

Ortiz, H. (1986). El Estado soberano del cauca 1858-1885. Tesis de magíster en historia. Bogotá: Universidad Externado de Colombia.

Páez, C. P. (1998). La administración fiscal de la renta del aguardiente en el Estado Soberano de Santander (1857-1886). Bucaramanga: Universidad Industrial de Santander. Monografía de Pregrado.

Pico, C. (2011). Fiscalidad bajo el dominio liberal en el Estado Soberano de Santander 18651879: un análisis de economía política. Tesis de Maestría. Bogotá: Universidad Nacional de Colombia.

Pinto, J. y Kalmanovitz, S. (2017). Fiscalidad en el Estado Soberano del Tolima, 1863-1885. Revista de Economía Institucional, 19(36), 175-201.

Rosenthal, J. (2015). The Fiscal History of Boyacá, 1863-1886: Liberal Dreams and Limited Resources. Revista tiempo\&economía, 2(2), 9-32.

Solano, S. P. (Comp.) (2007). Informe de los gobernadores de las provincias del Dpto. de Sucre, 1861-1882. Cartagena: Universidad de Cartagena.

Tirado Mejía, Á. (1989). El Estado y la Política en el siglo XIX. En: Nueva Historia de Colombia. Bogotá: Editorial Planeta.

Uribe, M. T. y López, L. M. (2008). La guerra por las soberanías. Memorias y relatos en la guerra civil de 1859-1862 en Colombia. Medellín, Instituto de Estudios Políticos - La carreta.

Velandia, R. (2004). Enciclopedia Histórica de Cundinamarca. Bogotá: Departamento de Cundinamarca, Secretaría de Educación.

Zapata, J. G. (2015). Reforma radical en el Estado de Santander, 1850-1885. Bogotá: Universidad del Rosario. 